\title{
Necropsy study of infarcts of prostate and prostatic urethra
}

\author{
T J JONES, A J HOWIE*
}

From the Department of Morbid Anatomy, The Institute of Pathology, The London Hospital Medical College, and the *Department of Pathology, University of Birmingham, The Medical School, Birmingham

SUMMARY A prospective study of 100 prostate glands taken at necropsy showed evidence of vascular disorders in 14. In 12 cases there was oedema, haemorrhage, or necrosis of the anterior wall of the prostatic urethra, and in two there was more extensive central infarction. There had been a period of hypotension in all 14 cases, at least 12 had had urethral catheterisation, and seven had had an operation within a month of death, four of which were for repairs of ruptured aortic aneurysm. Affected glands were the same size as a group of unaffected glands. We suggest that the prostatic urethra is at risk of ischaemia in hypotensive patients with a urethral catheter. This may be a contributory factor in urethral strictures after cardiovascular surgery.

Infarction of the prostate gland is a well described complication of hyperplasia of the gland. Although infarction is reported in various other circumstances, such as local trauma including surgery and systemic hypertension, there has been little investigation of the importance of such circumstances. ${ }^{1-3}$

The finding of infarction of the prostatic urethra and surrounding prostate at necropsy prompted us to carry out a systematic prospective study to try to identify factors associated with prostatic infarction.

\section{Material and methods}

Prostate glands were taken from 100 consecutive necropsies. Glands were removed intact, fixed in formol saline, trimmed of surrounding tissues and weighed. Three blocks were taken perpendicular to the urethra, at the internal meatus, the mid point and the distal end. These were embedded in paraffin wax, sectioned, and stained with haematoxylin and eosin. Clinical details were obtained from the patients' notes.

\section{Results}

In 14 of the 100 cases there was histological evidence of a vascular disorder of the prostate. In 12 cases there was oedema, haemorrhage, or necrosis of the prostatic urethra, affecting the anterior portion in seven cases and the whole circumference in five (fig 1).
In two cases there was recent haemorrhagic infarction of the central (intermediate) zone of the prostate, including the urethra (fig 2).

The age of these 14 patients ranged from 51 to 84

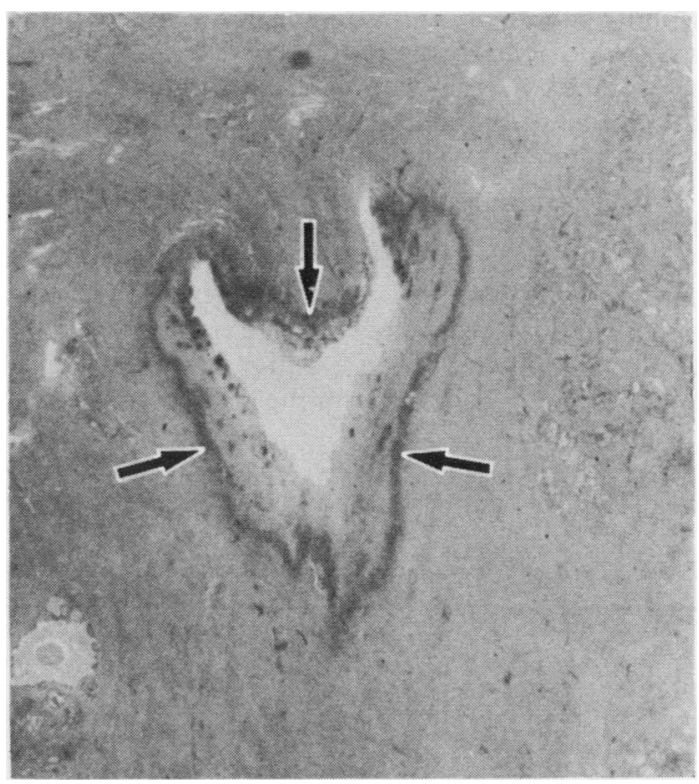

Fig 1 Congestion and necrosis of whole circumference of prostatic urethra with surrounding zone of acute inflammation (arrowed), in a man aged 71 years who died four days after repair of ruptured aortic aneurysm.

(Haematoxylin and eosin.) $\times 6$. 


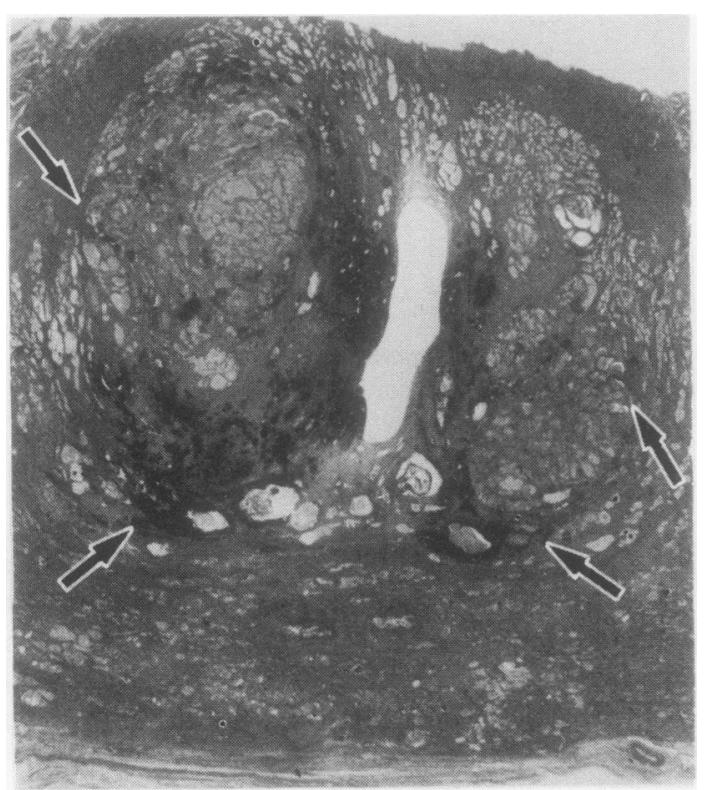

Fig 2 Infarcts (arrowed) surrounded by some haemorrhage, in central part of prostate gland of man aged 63 years who died three weeks after repair of ruptured aortic aneurysm. (Haematoxylin-van Gieson.) $\times 3$.

years. In seven cases there had been an operation within a month of death. In four this was for repair of a ruptured abdominal aortic aneurysm and the extensive infarcts were in two of these. In all patients there had been a period of hypotension from haemorrhage, sepsis, pulmonary embolism, and in one case, from cardiac bypass. A urethral catheter was known to have been present in 12 cases.

Comparison of these 14 cases with the remaining 86 cases showed that there was no difference in mean age or prostatic weight between the groups but that urethral catheterisation and ruptured aortic aneurysm were commoner in the group with vascular disorders (table 1).

Carcinoma of the prostate, unsuspected clinically, was found in four cases, none of which had vascular disorders. In only one case, without a vascular disorder, was there a lymphocytic infiltrate around the urethra suggestive of chronic urinary infection.

\section{Discussion}

We have shown that infarction of the prostate is a fairly common finding at necropsy and that factors other than hyperplasia of the gland are important in its pathogenesis. The anterior wall of the prostatic urethra seems to be the part of the prostate most susceptible to ischaemia. Most of the blood supply to the gland comes from branches of the internal iliac arteries that penetrate from the capsular surface. There are also a few vessels anterior to the urethra derived from the base of the bladder. ${ }^{45}$ The central part of the gland is furthest from supplying arteries and would be expected to be most at risk of hypoperfusion in conditions such as hypotension. Catheterisation is likely to contribute to the ischaemia of the prostatic urethra. Experimental foreign bodies in the urethra produce submucosal thrombosis and ischaemic necrosis. ${ }^{6}$ Urethral strictures are common in men after cardiovascular surgery, but only in those with urethral catheterisation, not in those with direct catheterisation of the bladder. ${ }^{7-9}$

The commonest condition associated with vascular disorders of the prostate was ruptured abdominal aortic aneurysm. This is likely to affect the prostatic circulation not only by producing hypotension but also by its association with atherosclerosis of the iliac arteries, which would further jeopardise blood flow to the central part of the prostate gland.

In our series there was no difference in size between glands showing infarction and those without infarction. This suggests that enlargement of the gland by hyperplasia is not itself a common cause of prostatic infarction in the absence of hypotension and urethral catheterisation.

The clinical importance of these vascular effects in the prostate is as yet undetermined. In patients who survive the insult causing necrosis of the prostatic urethra or central prostate the infarcted area will heal by scarring, and urethral stricture is a possible compli-

Table Factors associated with vascular disorders of the prostate

\begin{tabular}{llll}
\hline Factor & $\begin{array}{l}\text { Cases with vascular } \\
\text { disorders of prostate } \\
(n=14)\end{array}$ & $\begin{array}{l}\text { Other cases } \\
(n=86)\end{array}$ & $\begin{array}{l}\text { Significance } \\
\text { of difference }\end{array}$ \\
\hline $\begin{array}{l}\text { Mean (standard error of } \\
\text { mean) age (years) }\end{array}$ & $69.1(2.5)$ & $67.9(1.5)$ & Not significant $(t$ test) \\
$\begin{array}{l}\text { Mean (standard error of } \\
\text { mean) prostatic weight }(\mathrm{g})\end{array}$ & $55.9(4.8)$ & $56.0(2.4)$ & Not significant $(t$ test) \\
$\begin{array}{l}\text { No (\%) known to have } \\
\text { been catheterised }\end{array}$ & $12(85.7)$ & $35(40.7)$ & $\mathrm{p}<0.01\left(\chi^{2}\right)$ \\
$\begin{array}{l}\text { No (\%) with ruptured } \\
\text { aortic aneurysm }\end{array}$ & $4(28.6)$ & $5(5.8)$ & $\mathrm{p}<0.05\left(\chi^{2}\right)$ \\
\hline
\end{tabular}


cation. Whether stricture of the prostatic urethra will be important in such patients has not yet been confirmed as the urethral strictures occurring after coronary artery bypass surgery are reported to be in the membranous, bulbar, and penile parts of the urethra- that is, distal to the prostate. ${ }^{78}$

We are grateful to Mr AA Cooper for the photographs.

\section{References}

1 Mostofi FK, Leestma JE. Lower urinary tract and male genitalia. In: Anderson WAD, ed. Pathology. St Louis: CV Mosby, 1971:846-9.

2 Thackray AC. The male reproductive organs. In: Symmers WStC ed. Systemic pathology. Edinburgh: Churchill Livingstone, 1978:1587-8.
3 Rosai J. Ackerman's surgical pathology. St Louis: CV Mosby, 1981:850-2.

4 Clegg EJ. The vascular arrangements within the human prostate gland. Br J Urol 1956;28:428-35.

5 Warwick R, Williams PL. Gray's anatomy. Edinburgh: Longman, 1973:1350.

6 Painter MR, Borski AA, Trevino GS, Clark WE. Urethral reaction to foreign objects. J Urol 1971;106:227-30.

7 Ruutu M, Alftham O, Heikkinen L, et al. "Epidemic" of acute urethral stricture after open-heart surgery. Lancet 1982;i:218-9.

8 Abdel-Hakim A, Bernstein J, Teijeira J, Elhilali MM. Urethral stricture after cardiovascular surgery, a retrospective and a prospective study. J Urol 1983;130:1100-2.

9 Sutherland PD, Maddern JP, Jose JS, Marshall VR. Urethral stricture after cardiac surgery. Br J Urol 1983;55:413-6.

Requests for reprints to: Dr AJ Howie, Department of Pathology, The Medical School, Birmingham B152TJ, England. 